colleagues $^{4}$ is preliminary, they should be recognized for contributing to the foundation on which new treatments can be built. With increasing numbers of patients being diagnosed with $\mathrm{PAH}$, the pressure to find effective treatments remains high.

\section{References}

1. Rich S, Haworth SG, Hassoun PM, Yacoub MH. Pulmonary hypertension: the unaddressed global health burden. Lancet Respir Med. 2018;2600:577-9.

2. Wilkins MR, Aman J, Harbaum L, Ulrich A, Wharton J, Rhodes CJ. Recent advances in pulmonary arterial hypertension. F1000 Res. 2018;7:1-10.
3. Ghataorhe P, Rhodes CJ, Harbaum L, Attard M, Wharton J, Wilkins MR. Pulmonary arterial hypertension-progress in understanding the disease and prioritizing strategies for drug development. J Intern Med. 2017;282:129-41.

4. Miao H, Qui F, Zhu L, Jiang B, Yuan Y, Huang B, et al. Novel angiogenesis strategy to ameliorate pulmonary hypertension. J Thorac Cardiovasc Surg. 2021;161: e417-34.

5. Zhang Y, Zhang F, Wang X, Xie Y, Du J. Sequential and timely transfection of hepatocyte growth factor and monocyte chemotactic protein-1 ameliorates hyperkinetic pulmonary artery hypertension in rabbits. J Thorac Cardiovasc Surg. 2015; 150:634-43.e2.

6. Stenmark KR, Meyrick B, Galie N, Mooi WJ, Mcmurtry IF. Animal models of pulmonary arterial hypertension: the hope for etiological discovery and pharmacological cure. Am J Physiol Lung Cell Mol Physiol. 2009;279:L1013-32.

\title{
Commentary: A new treatment strategy for pulmonary arterial hypertension
}

\author{
Hiroshi Date, MD
}

Despite remarkable improvements in understanding the pathobiology ${ }^{1}$ and medical treatment for pulmonary arterial hypertension (PAH), it remains to be a severe and progressive disease. Pathologically, $\mathrm{PAH}$ is associated with a severe arteriopathy leading to small vascular occlusion, increased pulmonary artery pressure, right ventricular failure, and death. Current therapies are mainly targeted to 3 pathways: prostacyclin, nitric oxide, and endothelin. These therapies are very effective and have markedly improved the prognosis of patients with PAH, including idiopathic PAH. However, these therapies are not to cure PAH but to improve pulmonary hemodynamics by dilating pulmonary small vessels. When all medical treatment fails, lung transplantation remains to be the last hope.

In this issue of the Journal, Miao and colleagues ${ }^{2}$ report a rat experimental study to develop a new treatment strategy for PAH. ${ }^{3}$ The purpose of this study was to select a suitable

From the Department of Thoracic Surgery, Graduate School of Medicine, Kyoto University, Kyoto, Japan.

Disclosures: Author has nothing to disclose with regard to commercial support.

Received for publication March 29, 2020; revisions received March 29, 2020; accepted for publication March 30, 2020; available ahead of print April 11, 2020. Address for reprints: Hiroshi Date, MD, Department of Thoracic Surgery, Graduate School of Medicine, Kyoto University, 54 Kawahara-cho, Shogoin, Sakyo-ku, Kyoto 606-8507, Japan (E-mail: hdate@kuhp.kyoto-u.ac.jp).

J Thorac Cardiovasc Surg 2021;161:e436-7

$0022-5223 / \$ 36.00$

Copyright (c) 2020 by The American Association for Thoracic Surgery

https://doi.org/10.1016/j.jtcvs.2020.03.127

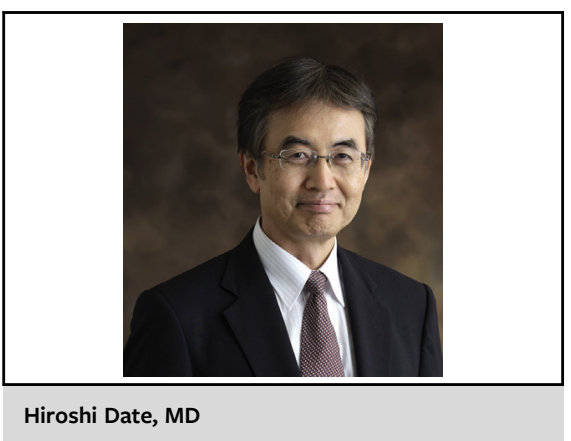

CENTRAL MESSAGE

The combination of proangiogenic and vascular stabilization factor transfection may promote angiogenesis and vascular maturation and thus may be a new treatment for pulmonary arterial hypertension.

combination of angiogenic and vascular stabilization factors to improve the proliferation and maturity of neovascularization of lung tissue. The contrast medium filling time and right pulmonary artery root diameter and hemodynamic parameters in hepatocyte growth factor + angiopoietin-1 (Ang-1) and vascular endothelial growth factor + Ang-1 groups were significantly decreased compared with the vehicle group. The authors concluded that hepatocyte growth factor + Ang-1 transfection and vascular endothelial growth factor + Ang-1 transfection alleviate PAH by promoting maturation and stability of new blood vessels, 
which may be potential candidates for PAH treatment. The authors are to be congratulated for completing this welldesigned animal study.

A monocrotaline (MCT)-induced pulmonary hypertension rat model has been widely used for studies on pulmonary hypertension, and the authors use this model in the present study. ${ }^{3}$ Endothelial injury and accumulation of inflammatory cells caused by MCT appear to have important roles in developing pulmonary hypertension. However, this model does not produce neointimal lesions, which are often observed in patients with severe PAH. Furthermore, MCT was given 2 weeks before the treatment, and the evaluation was done 2 weeks after the treatment. The scenario is quite different from clinical setting, in which $\mathrm{PAH}$, including idiopathic $\mathrm{PAH}$, is a disease that progresses over months and years.
Despite the aforementioned limitations, the result of this study is encouraging in the sense that the combination of angiogenic and vascular stabilization factors may be a new treatment strategy toward curing this devasting disease. Further studies using a large animal model are expected.

\section{References}

1. Tuder RM, Archer SL, Dorfmülle P, Erzurum SC, Guignabert C, Michelakis E, et al. Relevant issues in the pathology and pathobiology of pulmonary hypertension. J Am Coll Cardiol. 2013;62(25 suppl):D4-12.

2. Miao H, Qiu F, Zhu L, Jiang B, Yuan Y, Huang B, et al. Novel angiogenesis strat egy to ameliorate pulmonary hypertension. J Thorac Cardiovasc Surg. 2021;161: e417-34.

3. Stenmark KR, Meyrick B, Galie N, Mooi WJ, McMurtry IF. Animal models of pulmonary arterial hypertension: the hope for etiological discovery and pharmacological cure. Am J Physiol Lung Cell Mol Physiol. 2009;297:L1013-32. 